\title{
Arqueologia da primeira casa de fundição de ouro do Brasil, Iguape, SP
}

\author{
Maria Cristina Mineiro Scatamacchia* \\ Célia Maria Cristina Demartini** \\ Marcelo Pini Prestes*** \\ Antonio César Granero * * *
}

\begin{abstract}
SCATAMACCHIA, M.C.M.; DEMARTINI, C.M.C.; PRESTES, M.P.; GRANERO,
A.C. Arqueologia da primeira casa de fundição de ouro do Brasil, Iguape, SP.

R. Museu Arq. Etn., São Paulo, n. 22: 111-122, 2012.
\end{abstract}

Resumo: $\mathrm{O}$ objetivo do artigo é apresentar o resultado da pesquisa arqueológica realizada no quintal da casa onde atualmente está localizado o Museu Municipal da cidade de Iguape. A escavação arqueológica visou confirmar a indicação de o local ter sido originalmente a primeira casa de fundição de ouro, uma vez que em decorrência das várias transformações sofridas pela construção, não existia na atualidade nenhuma evidência material desta antiga atividade. $\mathrm{A}$ pesquisa realizada evidenciou os remanescentes que confirmaram a atividade de fundição de ouro no terreno comprovando a informação histórica.

Palavras-chaves: Arqueologia Histórica, Casa de Fundição, Iguape, Ouro

\section{Introdução}

casa onde hoje está localizado o Museu Histórico e Arqueológico de Iguape ${ }^{1}$ foi, de acordo com a informação textual, a

(*) Profa.Dra. Livre docente em Arqueologia Brasileira, Museu de Arqueologia e Etnologia da USP, Bolsista do CNPq

${ }^{(* *}$ Dra em Arqueologia, especialista em museu, Museu de Arqueologia e Etnologia da USP

$\left.{ }^{(* *}\right)$ Arquiteto, urbanista, mestre em Arqueologia, Faculdade da Cidade de Franca

$\left.{ }^{* * * *}\right)$ Bacharel e licenciado em História

(1) No começo da década de 1990 no âmbito do atual Programa Arqueológico do Baixo Vale do Ribeira, o museu foi implantado como veículo de divulgação da pesquisa e significou a primeira ação de extensão. $O$ fato teve também a intenção de valorizar o patrimônio arqueológico local e diminuir o processo de destruição que foi observado na etapa de levantamento (Scatamacchia et alli., 1988,1989) primeira casa de fundição de ouro do Brasil2 . Como no decorrer do tempo o local teve várias ocupações, na atualidade o edifício não apresenta evidências materiais do período em que era desenvolvida esta atividade.

Desse modo, a realização de uma escavação no quintal do museu constitui uma importante contribuição para identificar e confirmar a função passada do local.

A busca de ouro e metais preciosos sempre foi um atrativo para os portugueses em relação à exploração das novas terras, fato que pode ser documentado desde a expedição de Francisco

(2) Existe informação sobre a primeira casa de fundição ter existido na Vila de São Paulo, para fundir o ouro das minas do Jaraguá. 
de Chaves em $1531^{3}$, que tinha obtido informações sobre a existência de minas na região de Cananeia. Embora esta expedição tenha sido um desastre, as lendas, informações e esperanças sobre a existência de ouro continuaram a existir na antiga Capitania de São Vicente. Reforçando essas expectativas, em 1570, Heliodoro Eobanos encontrou jazidas auríferas na região de Iguape e no planalto do atual Estado do Paraná (Machado, 1997).

A descoberta do ouro na região do Vale do Ribeira que englobou Iguape, Curitiba e Paranaguá, não correspondeu à riqueza esperada e teve curta duração. Mas, tem o papel de ter dado início à história da mineração do ouro no Brasil.

A data da fundação Casa de Fundição de Iguape não tem concordância entre os historiadores, sendo que os historiadores locais e Young dão como certa a sua criação entre 1630 e 1632 (Fortes, 2000). Nesse sentido Young reforça essa posição:

"Não se pode precisar a época da fundação da oficina para o recebimento dos quintos reaes do ouro, porem devia ter sido uma das primeras do Brasil, pois pela ocasião da mudança da vila, que se efetuou entre 1620 e 1625, o povo edificou, como se diz em mais de um documento, a casa de sessão da Câmara e Cadeia, e uma outra para servir de oficina para fundição do ouro"

Outra informação dá o estabelecimento da Casa de Fundição de Iguape em 1653, por Pedro de Sousa Pereira, administrador geral das minas. "Passou o Provedor da Fazenda, e Administrador Geral das Minas Pedro de Souza Pereira à Villa de Paranagôa e de Igôape, afazer exame destas Minas, e por conta do estado dellas ordenou por mandado seo, datado em Igôape, a 30 de abril de 1653, aos officiaes da Camara de S.Paulo fizessem descer a Villa da Conceição para onde vinha caminhando, e dispondo o que sobre o particular das Minas convinha ao serviço de S.Magestade as 3 Aldeas doseo Real Padroado, a saber: a de S.Miguel, a de Marueri; e a dos Pinheiros, com todos os Indios, e suas famílias, a cargo

(3) Esta expedição foi descrita no Diário de Navegação de Pero Lopez de Souza. de Capitaens brancos, que estavam governando as ditas Aldeas....." ( Taques:87).

A proposta não foi concretizada pela intervenção dos camaristas de São Paulo, mas essa citação mostra a preocupação com o desenvolvimento do trabalho nas minas e dá uma informação importante sobre o problema da mão de obra nas minas.

Assim como a sua fundação o seu fechamento também não está precisamente documentado. A indicação comum é que ela tenha funcionado até 1760 , após ter passado por uma reforma e restauração em 1737.

Existe carta régia, de 1719, determinando que fossem mantidas as casas de oficinas de ouro e quintos reais de Iguape e Paranaguá, ordenando ainda a nomeação de provedor, tesoureiro e escrivão para estas oficinas. Essa situação mostra a existência da Casa de Fundição de Iguape ainda nesta data, mas talvez com um funcionamento precário por não possuir os empregados oficiais necessários. A atividade de mineração de ouro existia com certeza até 1735, em virtude da carta régia onde se instituía para as minas de ouro de Iguape a cobrança de quintos por bateia, como já era praticada nas Minas Gerais.

As ocupações posteriores, de quartel e cadeia ${ }^{4}$, apagaram os vestígios da antiga função. Existe a menção da transferência dos instrumentos usados na fundição de ouro terem sido encaminhados para o Museu Nacional. ${ }^{5}$

Desde 1969, o espaço passou a abrigar um núcleo de peças composto por objetos antigos e exóticos, mais um gabinete de curiosidade, sem uma definição de propósitos e de política de acervo. Essa situação foi alterada em 1989, com um projeto de reestruturação do Museu, através da parceria do Museu de Arqueologia e Etnologia da Universidade de São Paulo e a Prefeitura Municipal de Iguape, com o apoio da FAPESP

(4) A casa foi utilizada de forma precária como cadeia pública, até a inauguração do edifício hoje conhecido como Cadeia Velha.

(5) Informação contida no site da receita federal: www.receitafazenda.gv.br/Memoria/administração/repartições/colônia/casadefundicao 


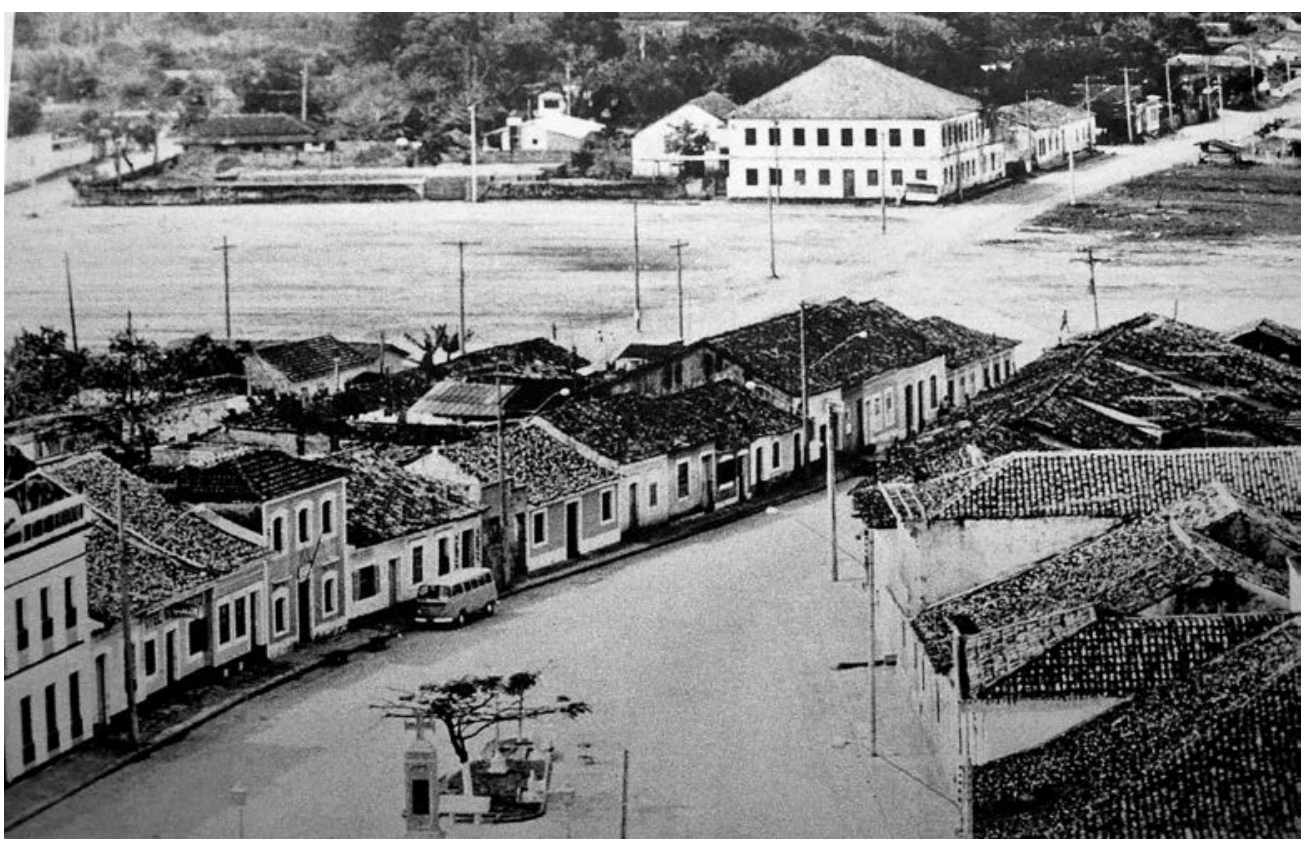

Fig.1. Foto da área central de Iguape, com o edifício de dois pavimentos da antiga Casa de Fundição, como era na década de 1950 ( apud. Lemos,1999)

(Fundação de Amparo à pesquisa do Estado de São Paulo) ${ }^{6}$ (Scatamacchia et alli.,1988;1990)

Essas datas servem como parâmetro para determinação do período da provável ocupação do edifício e do espaço escavado como oficina de fundição de ouro e dos outros processos depositários e transformacionais resultantes das ocupações sucessivas.

Os recursos auríferos do Vale do Ribeira foram deixados de lado com a descoberta das Minas Gerais, que pela sua riqueza acabou atraindo a atenção e o deslocamento de pessoas para o interior e conduzindo aos poucos a finalização do ciclo do ouro na região.

Entretanto, a atividade mineradora acabou atraindo milhares de aventureiros, propiciando um crescimento da Vila, a construção de um conjunto arquitetônico significativo e a consoli-

(6) A criação de um museu regional como veículo de divulgação da pesquisa na região veio de encontro à proposta de extensão do Programa Arqueológico do Baixo Vale do Ribeira, que é possibilitar que o conhecimento produzido possa ser utilizado como recurso didático dação do porto de Iguape. Mesmo levando em conta a opinião de alguns historiadores sobre a pouca importância do ouro do Vale do Ribeira, ele deve ter sido um volume considerável, para justificar a criação de uma Casa de Fundição na cidade, permanecendo como um marco para lembrar o passado áureo da região, que precisa ser resgatado e valorizado.

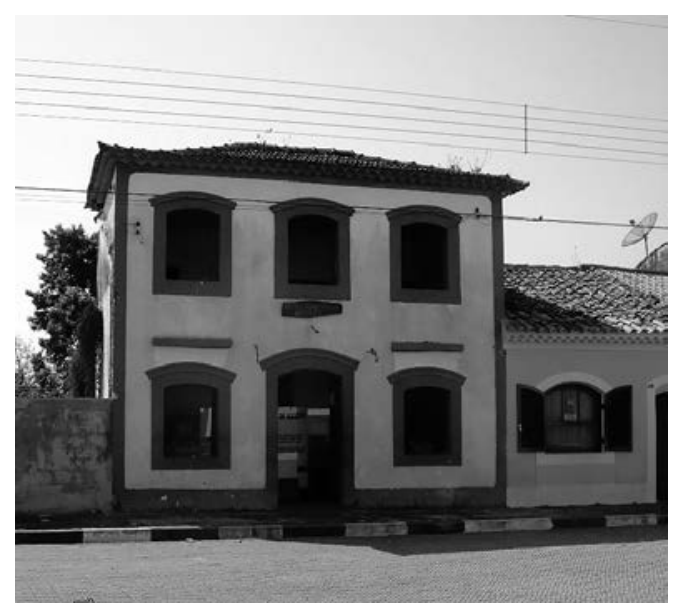

Fig.2. Imagem atual da antiga Casa de Fundição do Ouro, que abriga do Museu Histórico e Arqueológico 


\section{A casa de fundição de ouro}

As casas de fundição de ouro foram criadas pelo governo português para controlar a circulação do ouro e cobrar o quinto que the era devido. Elas foram os mais antigos órgãos de arrecadação de tributos sobre a mineração, perdurando até o princípio do séc. XIX, com a decadência das minas de ouro.

A função dessas casas era receber o ouro retirado das minas para fundi-lo em barras, onde ficava impresso o selo real, registrando-se o metal, que legalizado podia circular oficialmente. $\mathrm{O}$ cunho colocado nas barras as identificava como "ouro quintado", isto é do qual já fora deduzido o quinto.

A lei determinava que $1 / 5$ de todo ouro extraído deveria ser entregue à Casa de Fundição para ser fundido em barras com as armas reais.

A primeira casa de fundição do Brasil foi fundada em Iguape, na primeira metade do século XVII, para assegurar o pagamento do quinto para Portugal e foi chamada de Casa e Officina Real de Fundição do Ouro.
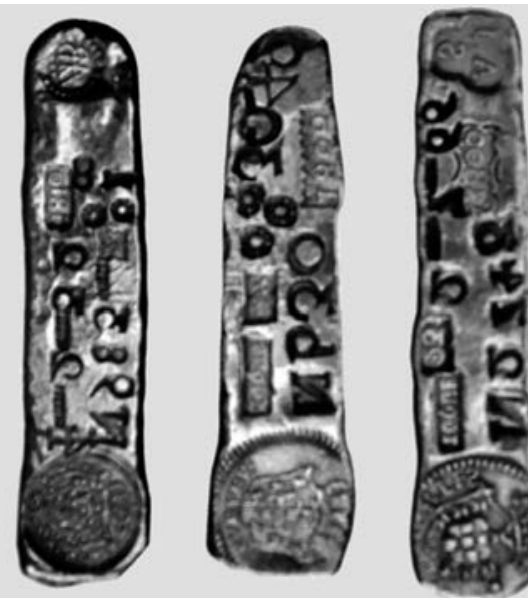

Fig.3. Exemplo de barras de ouro quintadas

A edificação atual é uma construção de dois pavimentos construída com a técnica de "taipa de pedra" ${ }^{7}$ comum a todo litoral paulista. Essa condição reforça algumas observações citadas sobre os exemplares atualmente conhecidos de Casas de Fundição do Ouro que são edificações de dois pavimentos, onde a parte superior era utilizada como residência do intendente, enquanto que no andar térreo funcionava o atendimento e administração (Silva e Pardi, 1989). No caso da Casa de Fundição de Iguape, as oficinas deveriam ficar na parte posterior, onde hoje é o jardim.

Segundo Eschwege, a organização das casas de fundição é excepcionalmente simples; o pessoal, porém, é numeroso e complicado. Há os escritórios, onde o ouro levado pelos mineiros é pesado e quintado; o forno referatário, onde é fundido e, em seguida, restituído; uma câmara de ensaio, onde é provado, por meio de risco, ou de copelação, ou ainda de inquantação.

Não existe uma informação precisa sobre a data em que a Casa de Fundição foi desativada, mas muitas referências são mencionadas sobre as ocupações posteriores e reformas do prédio. Desse modo o edifício existente é o resultado de inúmeras transformações e alterações do espaço original e o registro arqueológico resgatado e a cultura material remanescente dessa atividade é o reflexo desta situação.

Informações técnicas atuais ${ }^{8}$ descrevem o processo como sendo simples e rudimentar. A amostra de metal é fundida para através da copelação para determinar o quilate do ouro e onde eram extraídas as impurezas naturais, sendo que para realizar todo o processo são necessários pelo menos dois fornos.

$O$ processo de fundição foi descrito em detalhe da seguinte maneira por Eschewege em sua obra Plumo Brasilensis (p260):

\section{O processo de fundição de ouro nas casas} aludidas é, em resumo, o seguinte: o fundidor, recebido o material, coloca-o em um cadinho do tamanho apropriado e, em seguida, leva-o ao forno, cobrindo-o completamente de carvão vegetal muito bom. Manda assoprar lentamente até que o cadinho, coberto com uma tampa, se torne incandescente. Isso feito faz soprar

(8) MEtago, Metais de Goiás, citado em Silva e Pardi (1989:241)
(7) Essa pedra entaipada nada mais era que pedras irregulares de diferentes tamanhos, argamassadas com areia e cal dentro de fôrmas semelhantes aos taipais do planalto (Lemos,1999:228)
(1989.241) 
fragarosamente até ao conteúdo pequena porção de sublimado de mercúrio, que produz uma chama na superfície do puro liquido, rápida calcinação e volatização de ferro, cobre, antimônio e outros elementos estranhos, dando lugar a uma escória, que é retirada por meio de uma pinça. Adiciona-se o mercúrio até que a superficie do ouro não apresente nenhuma impureza. Quando completamente limpa e lustrosa, de cor esverdeada, como que transparente, o ouro é considerado purificado e retirado então do forno. Isso feito, é derramado em uma fôrma de ferro, banhada de gordura, onde fica a esfriar. É mergulhado em seguida na água, de onde é retirado e transformado em barras, a golpes de martelo, sobretudo nas pontas, até que se tornem um pouco achatadas.

Esse procedimento parece ter existido há muito tempo e perdurado através dos séculos, fato que pode ser visto nas ilustrações do século XVI, assim como em ilustrações egípcias.

A documentação iconográfica sobre a atividade de fundição de ouro é escassa e as principais representações encontradas são referentes aos fornos e forjas, mas algumas das representações levantadas merecem ser apresentadas.

Assim, o resultado da escavação realizada no quintal da Casa de Fundição de Iguape representa uma contribuição sobre as atividades e transformações deste espaço que teve no passado um papel pioneiro.

\section{A pesquisa realizada}

De acordo com as informações obtidas, provavelmente as oficinas de fundição do ouro deveriam estar localizadas na parte posterior do edifício, exatamente no local do jardim do atual museu. Nesse sentido, a pesquisa realizada em área urbana teve de considerar os aspectos inerentes a esta condição, levando em conta, tanto os aspectos técnicos do processo de formação do registro arqueológico quanto os sociais, uma vez que a intervenção está sendo feita em um local onde existe um cotidiano de utilização, que no caso do museu é uma área pública.

O fato de a pesquisa estar sendo realizada em uma área que teve várias intervenções e transformações do contexto original diminui o seu potencial informativo, mas este fato não representa a ausência de informações, como pudemos observar em experiências realizadas em vários sítios fortemente impactados por ações antrópicas. Mesmo não resgatando e analisando o registro de deposição primário, testemunho direto da atividade, as evidências recuperadas representam dados importantes para o conhecimento da atividade do local.

A arqueologia de áreas de atividade, como a que hoje é o quintal do Museu, indicado como o local das oficinas, vem de encontro à necessidade de resgatar dados materiais que não constam da documentação textual sobre o tema.

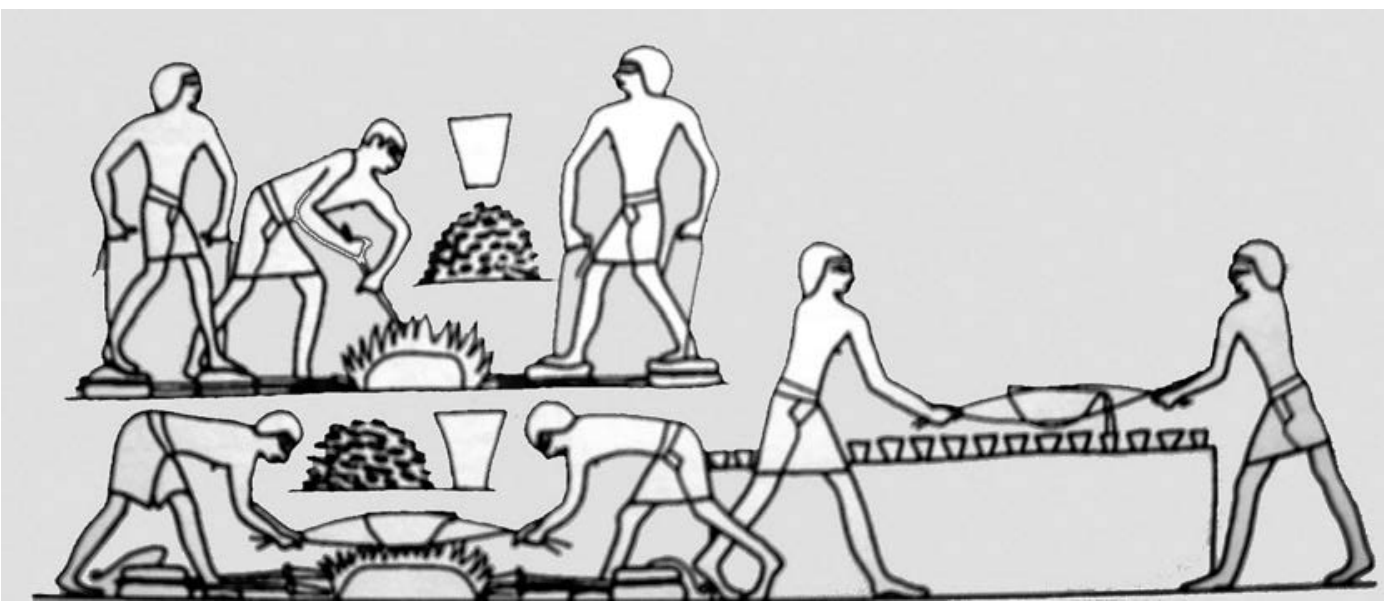

Fig.4. Atividade mineradora, com forno e os cadinhos para fundição, pintura na parede da tumba do Vizir Rekhmire, em Tebas, Egito (apud.Arruda,1997) 

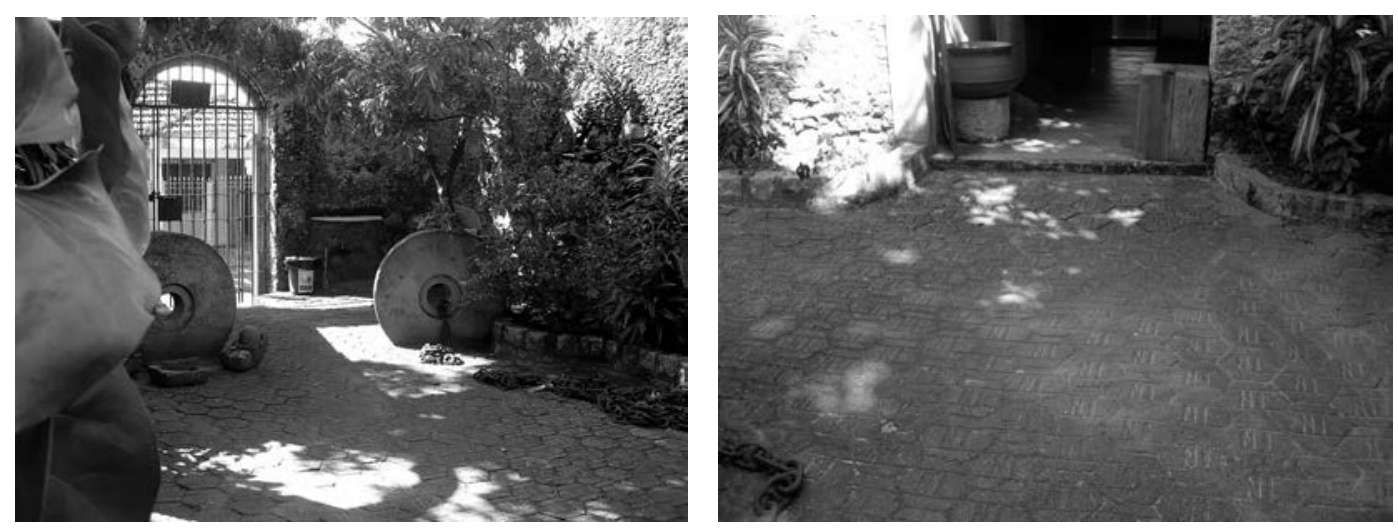

Fig.5. Aspectos do quintal do Museu Histórico e Arqueológico, onde provavelmente devem ter funcionado as oficinas da Casa de Fundição do Ouro
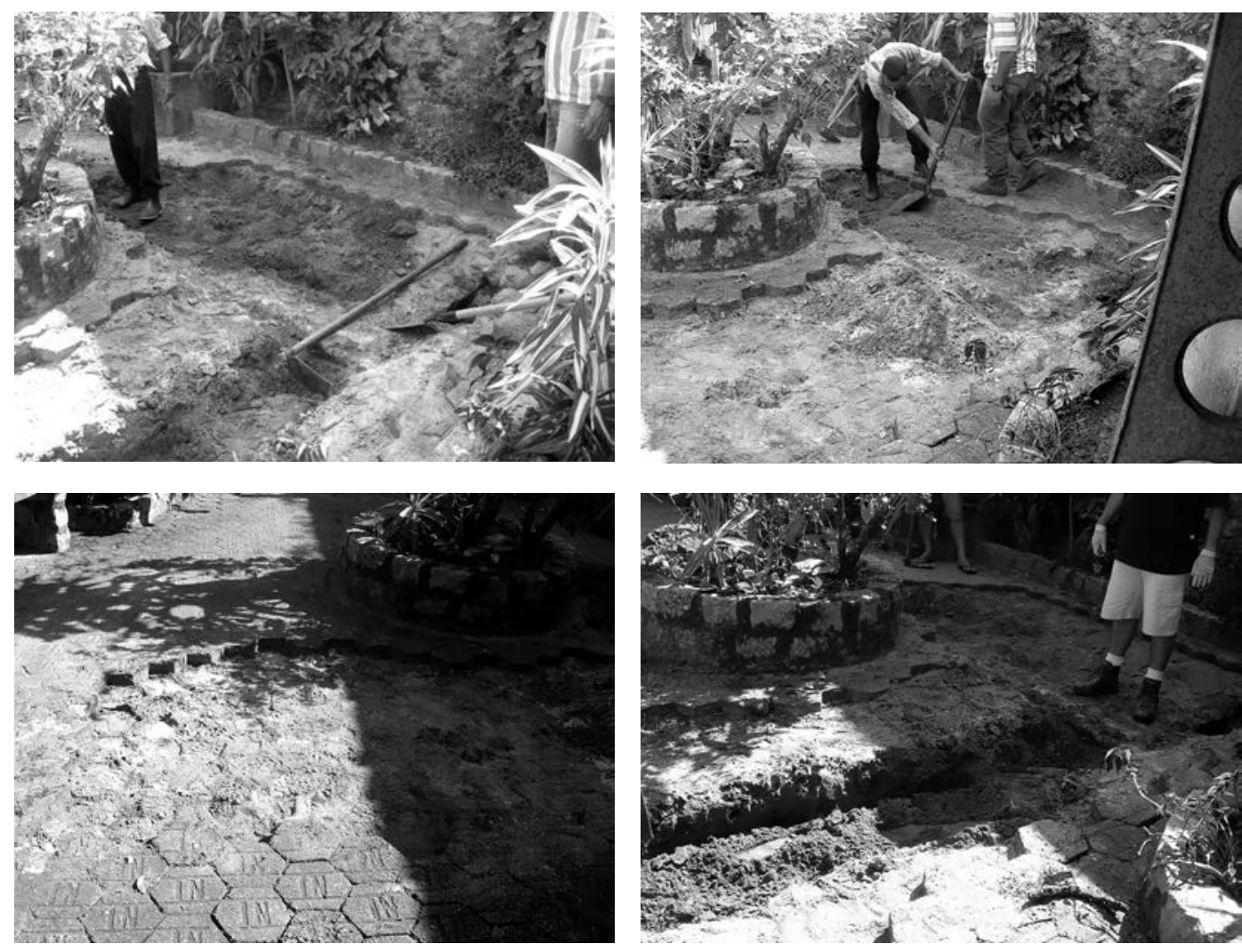

Fig.6. Retirada das lajotas e início das escavações

A proposta metodológica para o resgate do registro arqueológico do local iniciou-se com a divisão da área em duas partes para a realização da pesquisa, essa decisão visou a possibilitar o trânsito no local. O passo seguinte foi a retirada das lajotas de cimento e a realização de uma trincheira exploratória para evidenciar a estratigrafia existente. A técnica de escavação levou em conta os extratos naturais, para decapar e evidenciar os remanescentes materiais que permaneceram no registro arqueológico. 
A estratigrafia evidenciada mostrou a existência de uma camada de areia de aproximadamente $15 \mathrm{~cm}$ colocada para o assentamento das lajotas, sendo que sob este piso existia $40 \mathrm{~cm}$ de aterro colocado para nivelar o terreno, uma vez que existe um desnivel entre a parte anterior e a posterior do terreno, que pode ser visto claramente no portão do quintal que dá para a rua XV de Novembro. Abaixo desse entulho foi evidenciado o piso de ocupação, $60 \mathrm{~cm}$ do piso atual.

A primeira trincheira exploratória localizada próxima ao prédio do atual museu mostrou o solo estéril de areia branca ocorrendo a $80 \mathrm{~cm}$ de profundidade. Essa informação norteou a escavação, localizando à as atividades na parte posterior do terreno.

\section{No entulho, informações sobre a cidade}

O material cultural presente no entulho que compõe o aterro é muito diversificado e significativo como indicador social, uma vez que os objetos descartados pertencem a vários momentos do processo de ocupação. Mesmo
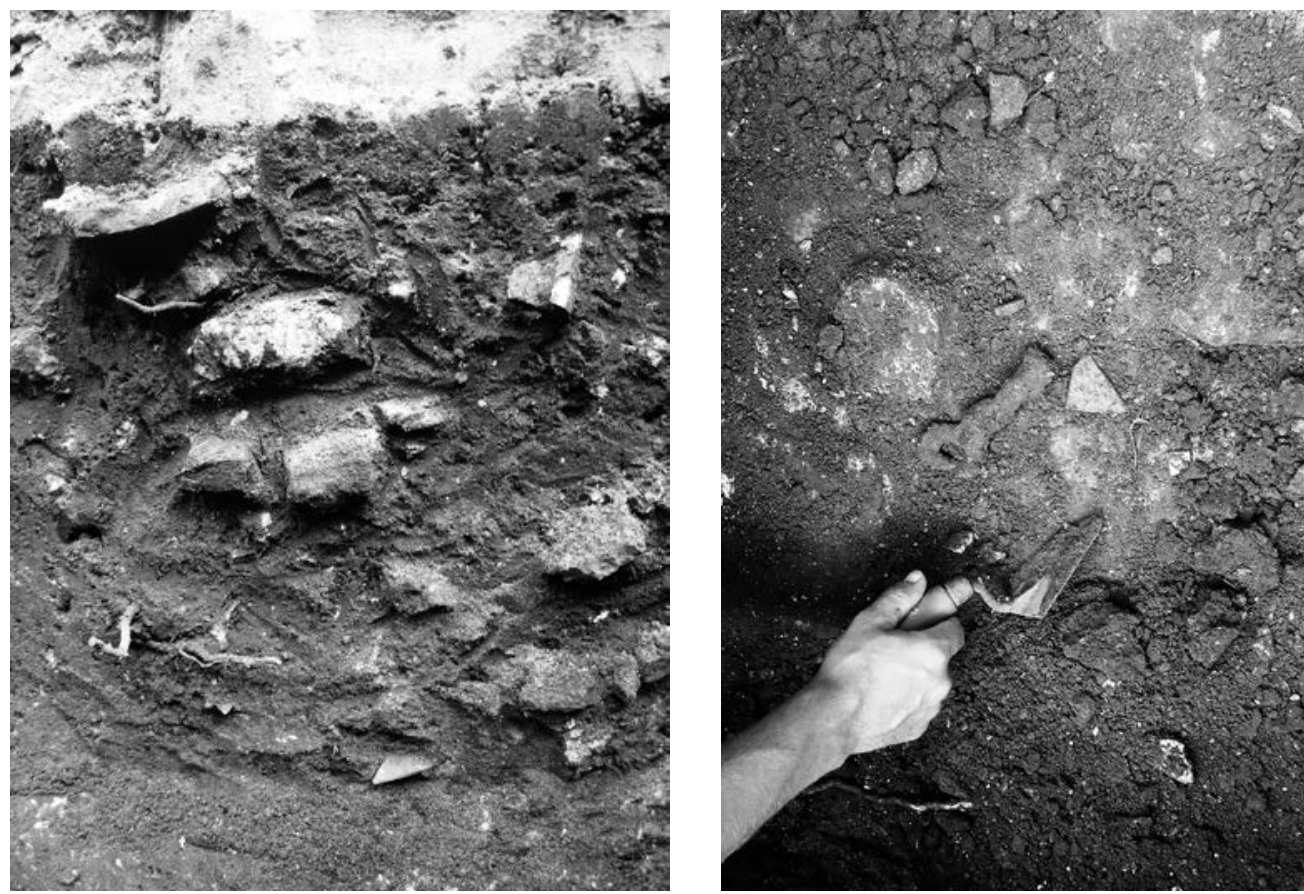

fora do contexto, os objetos identificados permitem a realização de uma série de inferências em relação aos hábitos sociais e econômicos.

O resultado da análise realizada mostrou a presença de artefatos provenientes de moósseos, provavelmente refugo de alimentação. Vale salientar a presença de louça inglesa com tipos decorativos semelhantes àqueles encontrados nos sítios históricos em geral e que correspondem ao gosto de uma sociedade local que estava se formando tendo como referências os grandes centros urbanos. Esse tipo de louça simbolizava a riqueza e status relacionados à uma classe burguesa emergente, e sua presença na cidade era propiciada pelo comércio através do Porto Grande.

A grande quantidade de vestígios e artefatos de ferro no entulho pode ser proveniente da própria atividade local, sendo esse um dos elementos esperados no registro arqueológico de uma oficina de fundição.

Esse conjunto de cultura material resgatado do entulho, embora não esteja diretamente mentos cronológicos diferentes e de vestígios

Fig.7 - Perfil estratigráfico mostrando a camada de entulho 
Arqueologia da primeira casa de fundição de ouro do Brasil, Iguape, SP

R. Museu Arq. Etn., São Paulo, n. 22: 111-122, 2012.
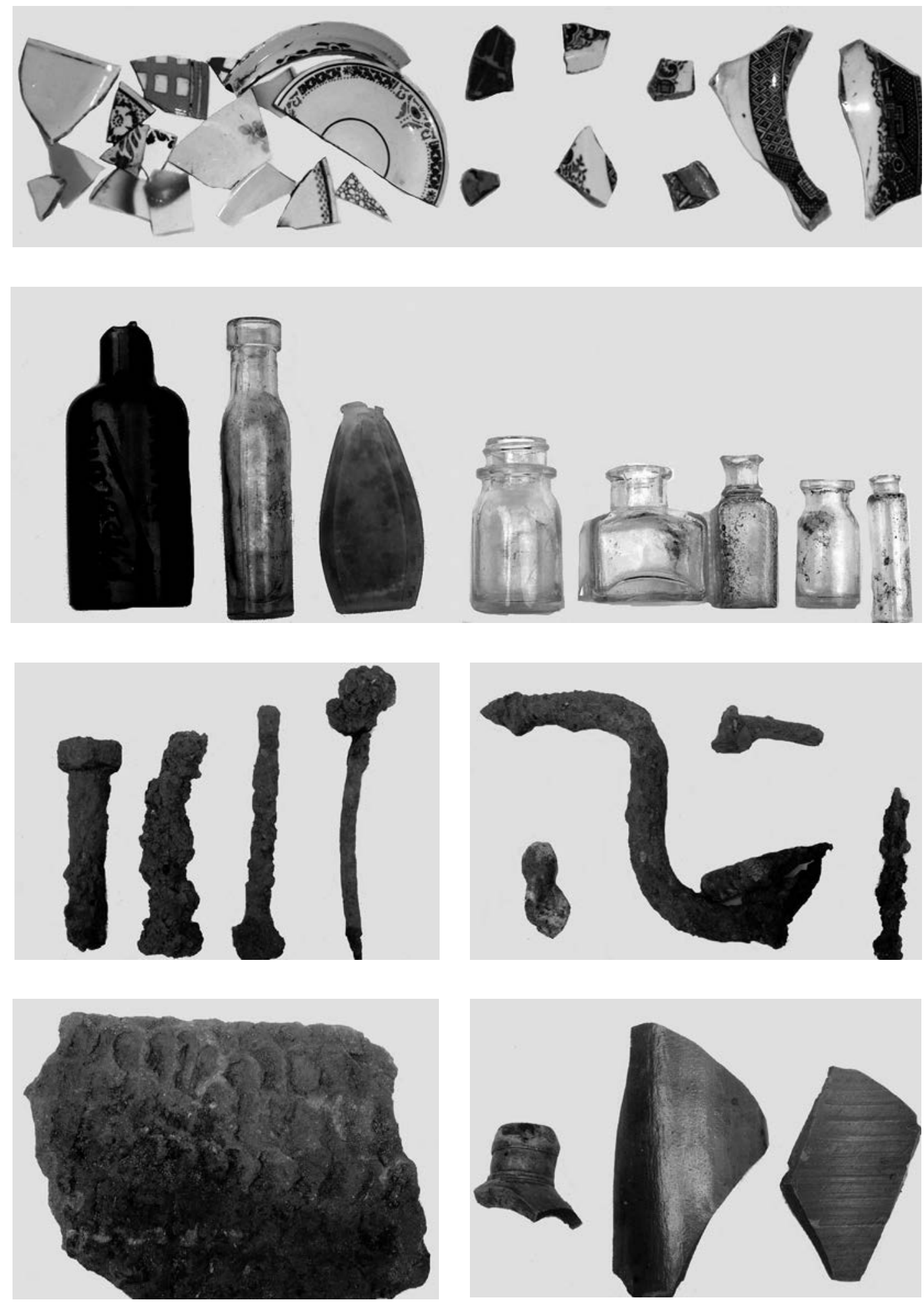

Fig.8 - Amostra do material encontrado no entulho 


\begin{tabular}{|c|c|c|c|c|}
\hline Metal & Louça & Vidro & Cerâmica & Osso \\
\hline Chave & $\begin{array}{c}\text { Faiança portu- } \\
\text { guesa }\end{array}$ & Garrafas & Cerâmica indígena & Dentes de cavalo \\
\hline $\begin{array}{c}\text { Parafusos, } \\
\text { cravos }\end{array}$ & $\begin{array}{c}\text { Faiança fina } \\
\text { inglesa }\end{array}$ & Vidro de remédio & $\begin{array}{c}\text { Cerâmica neobra- } \\
\text { sileira }\end{array}$ & Ossos de porco \\
\hline Dobradiça & $\begin{array}{c}\text { Faiança branca } \\
\text { fina }\end{array}$ & Vidro de perfume & Vértebras de peixe \\
\hline $\begin{array}{c}\text { Fragmentos sem } \\
\text { identificação }\end{array}$ & $\begin{array}{c}\text { Faiança branca } \\
\text { grossa }\end{array}$ & $\begin{array}{c}\text { Fragmentos não } \\
\text { identificados }\end{array}$ & indígena & $\begin{array}{c}\text { Ossos não identi- } \\
\text { ficados }\end{array}$ \\
\hline Escorias de ferro & \multicolumn{2}{|c|}{} & & \\
\hline
\end{tabular}

Tabela 1 - O material resgatado no entulho

ligado ao contexto de funcionamento das atividades da antiga Casa de Fundição, fornece elementos importantes sobre os hábitos e poder aquisitivo da cidade. A característica cultural dos artefatos é semelhante ao material encontrado nos outros sítios na área urbana9. Mesmo fora do seu contexto original de deposição, o material possui um potencial informativo que não pode ser desprezado.

O material que compõe o entulho pode ser proveniente de descarte local e corresponde às atividades de caráter doméstico da Casa de Fundição, que deveria ter a sua parte superior ocupada como moradia. A análise do material aponta para louças e vidros de uso doméstico, sendo que os vestígios ósseos devem ser restos alimentares.

Os vestígios culturais indígenas, fragmentos de cerâmica e cachimbo, podem ser provenientes da movimentação de terra do próprio local, considerando que parte da cidade de Iguape está sobre uma aldeia indígena, ou ter sido trazido junto com o material do aterro.

\section{O piso original da oficina da casa de fundição}

A primeira trincheira estratigráfica exploratória feita na área a ser pesquisada identificou um alicerce, de uma construção atual, localizado

(9) Praça da Matriz, Porto Grande e Porto do Ribeira. no início da sua extensão. Na sua sequência, cinco metros do trecho inicial foi identificado o antigo piso de ocupação localizado a $60 \mathrm{~cm}$ de profundidade, caracterizado por uma de terra compacta de coloração escura. Nessa camada foram evidenciadas pedras indicando uma estrutura, que quando escavada mostrou a presença de um espesso vasilhame de ferro, cuja alça estava solta em decorrência do avançado estado de decomposição da peça.

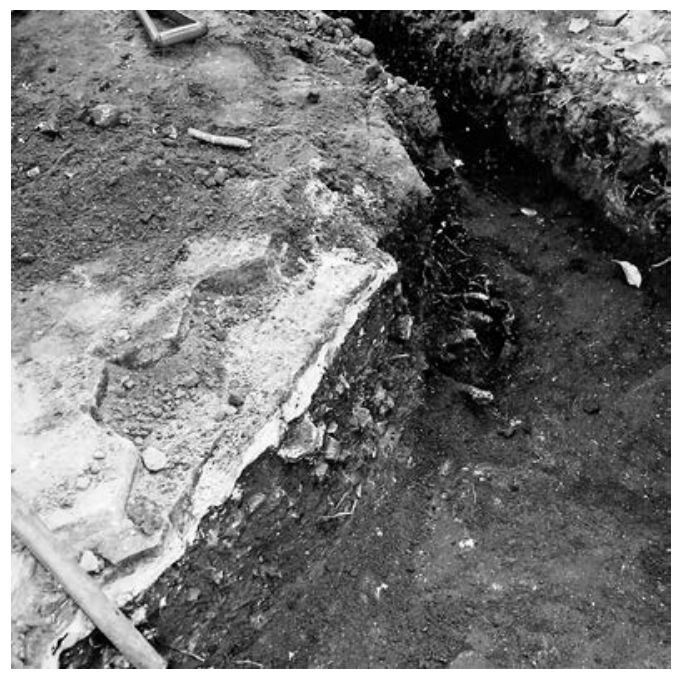

Fig.9. Perfil estratigráfico mostrando a camada de entulho

No solo compacto detectado abaixo da camada de entulho, foram identificadas pedras 


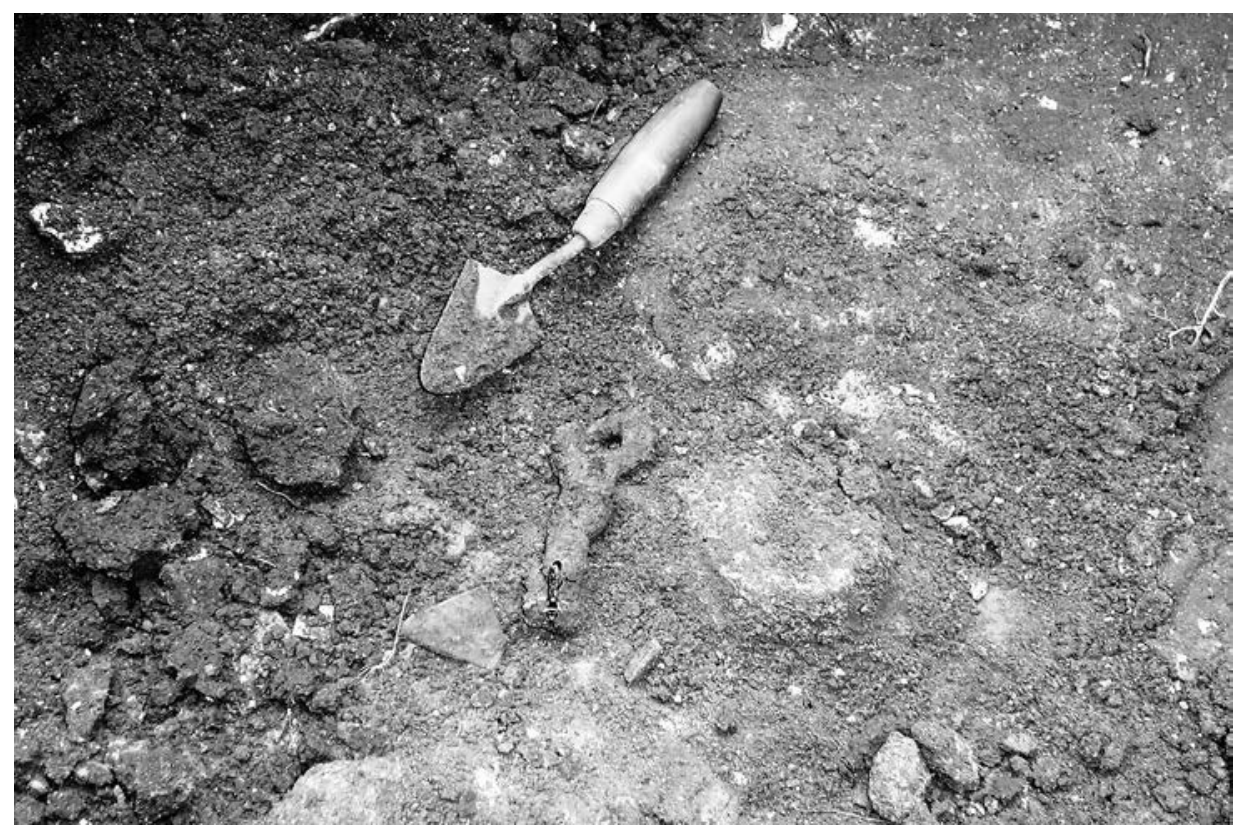

Fig.10. Piso original de ocupação, com o aparecimento dos primeiros vestígios de pedra e de uma peça metálica
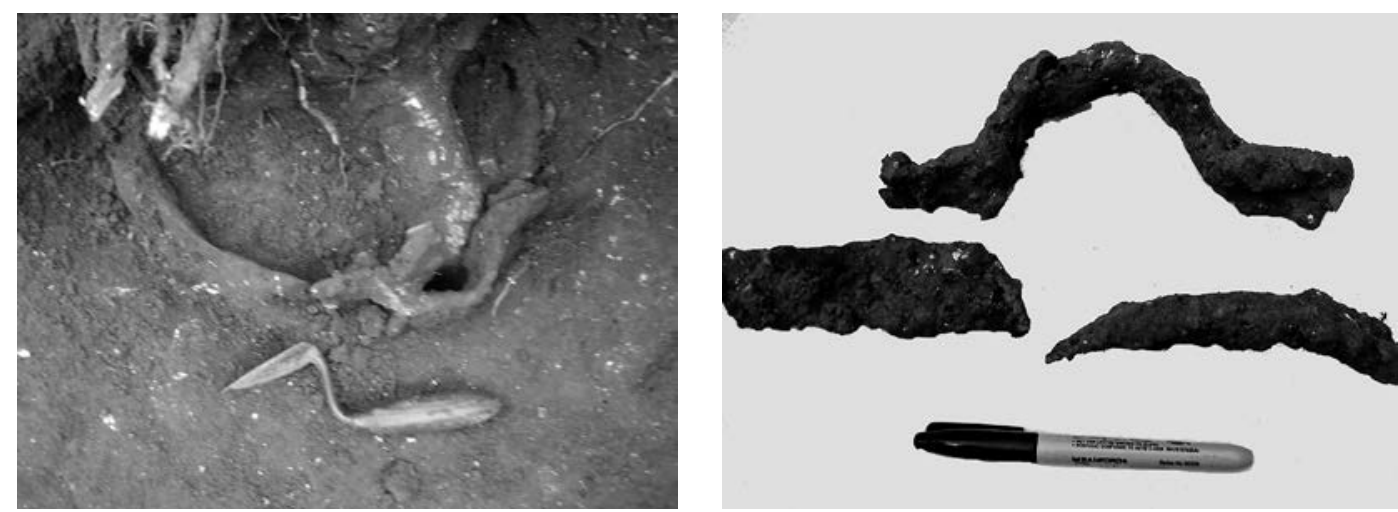

Fig.11. Peça metálica enterrada e alça e bordas que se encontravam deslocadas

e vários fragmentos de ferro, alguns são artefatos em estado de decomposição e outros são provavelmente borras de fundição ${ }^{10}$.

A abertura e limpeza da área do entorno da peça metálica evidenciou fragmentos de

(10) Borras são resíduos de bórax solidificado fundido com outras impurezas resultantes do processo de fundição do ouro ferro, carvão, conchas e de aglomerado de cal, provavelmente composto por ossos e conchas trituradas.

Nas proximidades dessa peça e neste mesmo nível foi encontrado um cadinho, primeiro vestígio concreto das atividades de fundição. Ele é de grafite e está com muitas concreções, estava inclusive com um seixo agregado à parede. 

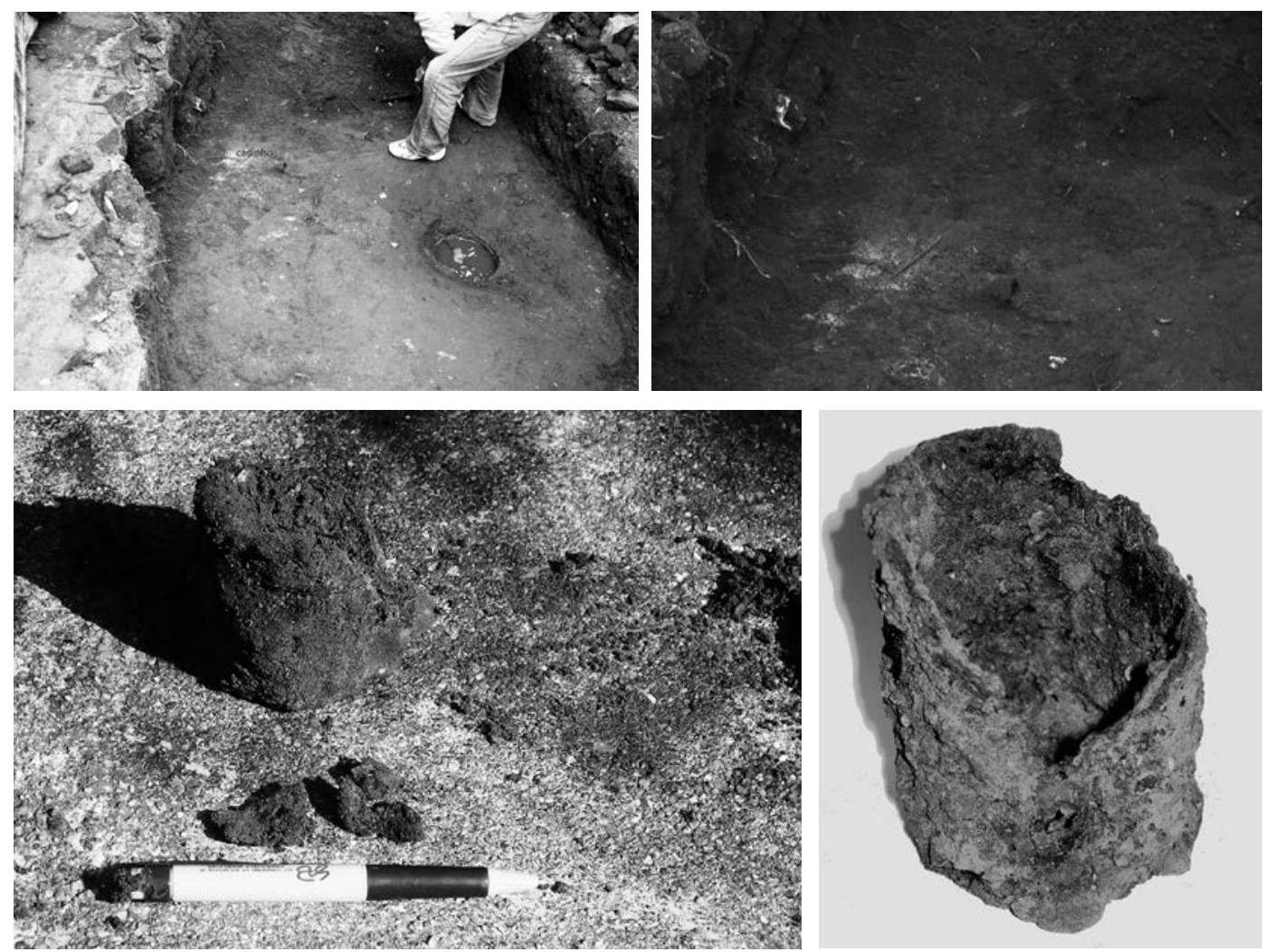

Fig.12 - Processo de localização, identificação e resgate do cadinho

A análise realizada no material do interior do cadinho e do fragmento de uma vasilha de cerâmica identificou a presença de vestígios de ouro ${ }^{11}$.

A peça estava em avançado estado de decomposição e com muitas concreções metálicas na parte externa ${ }^{12}$. Essa peça é um indicador preciso do processo de fundição que foi realizado na área onde hoje é o quintal do museu. No mesmo nível de ocupação e caracterizando a atividade de fundição foram encontrados fragmentos de cerâmica também com vestígios metálicos no interior.

A continuação da retirada do entulho do solo, identificado como da atividade de fundição, evidenciou um área de terra escura provavelmente decorrente da queima de material.

(11) A análise foi feita pelo IPEN-USP

(12) $O$ material que estava no interior da peça foi retirado para análise.

\section{Considerações sobre a pesquisa}

As referências literárias apontavam o local que hoje abriga o atual Museu Histórico Arqueológico de Iguape como tendo sido o da primeira casa de fundição de ouro. Entretanto, não existia até a realização desta pesquisa nenhum vestígio material que comprovasse tal proposição.

O espaço pesquisado estava totalmente descaracterizado depois de o edifício ter passado por várias alterações, diferentes atividades e aterro, mas a pesquisa arqueológica conseguiu resgatar informações que comprovam a atividade de fundição no local, mesmo realizada em uma porção limitada do espaço que hoje é o quintal do Museu.

Nesse sentido, o resultado da pesquisa arqueológica constitui um dado importante para a construção da história regional e uma contribuição para entender o processo de desenvolvimento da atividade de mineração do ouro no Brasil. 


\title{
SCATAMACCHIA, M.C.M.; DEMARTINI, C.M.C.; PRESTES, M.P.; GRANERO,
}

Archaeology of the Brazil's first gold casting house, Iguape, SP. R. Museu Arq. Etn., São Paulo, n. 22: 111-122, 2012.

\begin{abstract}
The objective of this article is to present the results of archaeological research carried out in the backyard of the house where today is located the Iguape city Municipal Museum. The archaeological excavation aimed to confirm the appointment of the site have been originally the first gold casting house, since due to the various transformations suffered by construction, did not exist at the present time no material evidence of this ancient activity. The survey showed the remnants which confirmed the gold casting activity on the ground proving the historical information.
\end{abstract}

Keywords: Minting House, Historical Archaeology, Iguape, Gold

\section{Referências bibliográficas}

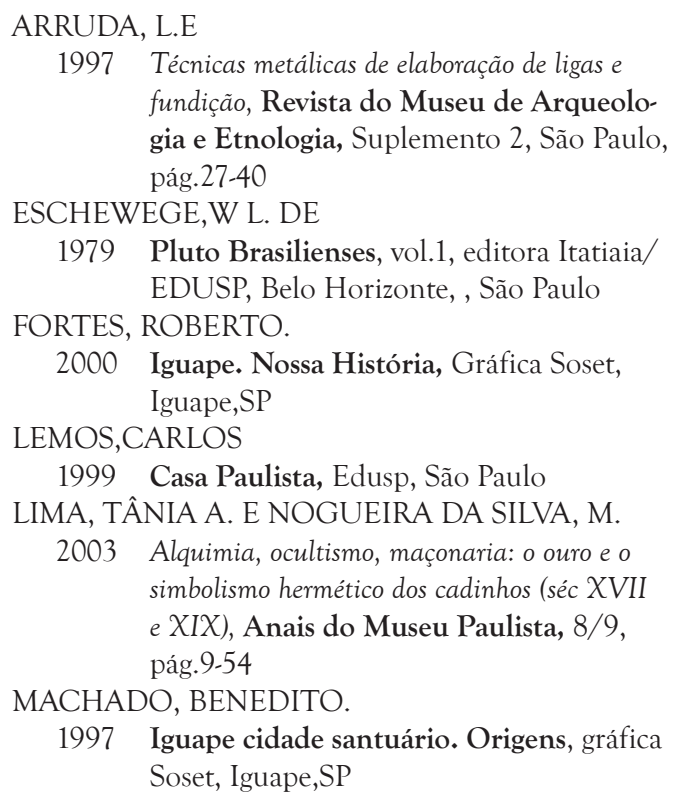
fundição, Revista do Museu de Arqueologia e Etnologia, Suplemento 2, São Paulo, pág. 27-40

ESCHEWEGE,W L. DE

1979 Pluto Brasilienses, vol.1, editora Itatiaia/ EDUSP, Belo Horizonte, , São Paulo

FORTES, ROBERTO.

2000 Iguape. Nossa História, Gráfica Soset, Iguape,SP

LEMOS,CARLOS

1999 Casa Paulista, Edusp, São Paulo

LIMA, TÂNIA A. E NOGUEIRA DA SILVA, M.

2003 Alquimia, ocultismo, maçonaria: o ouro e o simbolismo hermético dos cadinhos (séc XVII e XIX), Anais do Museu Paulista, 8/9, pág.9-54

MACHADO, BENEDITO.

1997 Iguape cidade santuário. Origens, gráfica Soset, Iguape,SP

SCATAMACCHIA, M. CRISTINA MINEIRO, CERÁVOLO, SUELY, BRAVO, LUIZA E HIRATA, ELAINE

1990 A recuperação do passado: uma exposição sobre os vestígios da ocupação humana no baixo vale do Ribeira, Dédalo, 28, São Paulo, pág. 15-37

SCATAMACCHIA, M.CRISTINA, HIRATA, ELAINE, BRAVO,LUIZA E CERÁVOLO, SUELY

1988 A divulgação da pesquisa arqueológica junto à comunidade: o papel do Museu Regional, Dédalo, 26, São Paulo, pág.97-109

SILVA, CATARINA E.F. DA E PARDI, MARIA LUCIA F.

1989 A pesquisa arqueológica na Casa de Fundição do Ouro de Goiás,GO, Dédalo, publicação avulsa 1, São Paulo,pág.238-261

TAQUES DE A.P.L., PEDRO

$\mathrm{n} / \mathrm{d}$ Informação sobre as minas de São Paulo, editora Comp. Melhoramentos de S.Paulo, São Paulo-Cayeiras-Rio, pág.65-168 